\title{
Study on the Western Development and the Protection of the Human Rights of the Ethnic Minorities
}

\author{
Jing Luo ${ }^{1}$ \\ ${ }^{1}$ Xi'an Peihua University, Xi'an, Shaanxi 710125
}

Keywords: human rights; ethnic; development and protection

\begin{abstract}
With the successful implementation of China's western development strategy, the issue of the rule of law in the western region has become a key and difficult point for China's implementation of the strategy of administering the country by law. To explore the rule of law in the development of the western region, it is necessary to discuss it in the name of "diversification of law," and analyze in detail the value of national law and the cultural awareness of the common law of ethnic minorities.
\end{abstract}

\section{Introduction}

The predecessor of the current Constitution expressly solemnly declares that "The People's Republic of China is a unitary multi-ethnic country jointly created by people of all nationalities in the country". As a multi-ethnic country, our country guarantees the rights and interests of many ethnic groups, especially the human rights of ethnic minorities. The level of protection directly affects national unity, social stability, national security and economic development. Since the founding of the People's Republic of China, China has formulated a series of guidelines and policies for the protection of the rights and interests of ethnic minorities and the handling of ethnic issues, and has made principled provisions in the Constitution. These contents have played a role in strengthening national unity and promoting economic development in ethnic minority areas. However, with the deepening of reform and opening up and the development of a market economy, it is necessary to protect the rights of minority ethnic groups from a higher legal level, constitutionally.

\section{Western Development Legal System}

There are two representative paradigms in the study of law in China's legal circle: one is the modern paradigm, and the other is the localization paradigm. The fundamental difference between the modern paradigm and the localization paradigm lies in the different definitions of legal concepts. The paradigm of modernization defines law from the perspective of politics and adheres to the monistic legal concept. Emphasizes the inevitable connection between law and the state, and considers that the law is a behavioral rule formulated or recognized by the State. As for those social norms that are similar or identical to the law in function, they play an auxiliary and reinforcing role in law (such as the constitution of the political parties, associations, and township regulations). The people's covenant, etc.) may be called "quasi-law" or "class law," but it cannot be attributed to the scope of law. The modernization of the legal system is a process in which the modern law established by the country replaces various local, non-governmental, and traditional customs and rules [1]. The rule of law is the situation in which modern law established by the country dominates the world. The localization paradigm defines the law from the perspective of sociology and holds a pluralistic view of law (also known as legal pluralism). Legal pluralism understands law from the perspective of social norms and social order. It holds that true law is a function of people's lives and is taken for granted as a normative and order. The order of social life is impossible at any time, and It should not only be constituted by the laws enacted by the State. Therefore, legal pluralism actually expands the scope of the concept of law, emphasizing that law is a rule that actually plays a role in social life. It holds that law does not only refer to the national law, but also includes the rules 
of popular practice (folk law). This point of view provides a theoretical basis for our study of the rule of law in western development and the culture of customary law of ethnic minorities.

\section{To Realize the Positive Interaction between the National law and the "Customary Law" in the Development of the Western Region}

The cultural barrier between national law and customary law determines the arduousness and long-term nature of the rule of law in the development of the western region. It requires us to have a comprehensive and rational understanding of the relationship between the two. The above analysis has shown that national law has a strengthening effect on customary law, and customary law also has a positive influence on national law: the importation of a national law into the western region will help the western social subjects to step out of the traditional legal world, and with certain obstacles to society. The backward legal culture (concept) between progress and legal growth is discriminated against. Under the guidance of the new legal concept, the legal value of the times is more deeply understood at a new historical level, and the legal tradition is given a new form of existence and history. Vitality, to achieve the integration of tradition and modernization, promote the modernization of the rule of law; the lack of national law provides a space for the existence of customary law, the customary law tradition in the western region is still an important social cohesion mechanism in the region, it is not only conducive to the west The ecological and environmental protection and human rights protection in the region are also conducive to the western community's acceptance of the country's laws from the point of view of the customs and the psychological protection of the national law. It should be noted that although the content of customary law is in harmony with the modern legal system, it also contains a lot of backward content [2]. Customary law is distinctly different from state law in terms of thinking style and value pursuit. For example, customary law contains a lot of content that embodies male inferiority and female patriarchal patriarchal thought; the inadequacy of the informality and dispersion of customary law tends to cause people to observe with the non-observance of random. These contents and defects are obviously inconsistent with the requirements of the modern legal system. While regulating and influencing social life, they will inevitably hinder the implementation of the national law and undermine the authority that the state law should have. On the other hand, people's rationality is limited, and even more elaborate laws and regulations cannot fully cover the society, and provide precise regulations for various transactions or exchange activities in the process of marketization. The law is bound to have flaws and deficiencies; because in the legislative and judicial activities, the universal implementation of state laws and regulations is a basic requirement, ignoring the immense role of customary law in people's legal actions, and many orders have failed to emerge. The phenomenon of "avoidance of the law" is forbidden. Therefore, national law and customary law have a harmonious and consistent side, but there are also differences, oppositions and even contradictions and conflicts. Based on this, we discuss the relationship between national law and customary law. Its purpose is not to deny or exclude customary law in the western region by advancing the state law, let alone to build a modern legal system in the western region with customary law as the leading factor. Coordinate and handle the relationship between the two and solve the interaction and connection between these two normative knowledge. This is the main attack point and breakthrough point for strengthening the construction and guarantee of the rule of law in the development of the western region. If this is not done, it may cause confrontation and tension between the country's rule of law resources and the local traditional rule of law resources in the western region, and impede the process of the modernization of the rule of law in the western region.

There must be certain differences between the customary law and the legislative thinking of the legislators of the state law. When the legislators legislate their attitude towards the customary law, they should deal with differences rather than eliminate differences. Montesquieu believes that "there are different systems of law, and that human reason is so grand and noble, because it can well recognize the main relationship between what the law is trying to achieve and which system, and not to upset those who should Principles that govern humanity.” Therefore, legislation should be 
consistent with customary law, and it must not violate the most basic ethical ethical norms, and must take into account the actual rules of life of customary rules and regulations. A place and a nation must form certain rules of civil life in a certain empirical society. As legislators, we must be careful not to deny these rules. When we make laws, we can only follow their own characteristics, and we cannot reverse them. National law may directly absorb the beneficial norms of customary law, or set up provisions for flexibility to provide institutional guarantees for the absorption of useful norms of customary law. For example, in the civil laws that regulate the relationship between the human and the property of equal subjects, the flexible language such as "custom" and "goodness and custom" can be used as the basis for absorbing the norms of customary law. In the construction of the legal system in the western region, we should further improve the legislative system in ethnic autonomous areas, strengthen the self-government legislation, and, without violating the basic system of the state and the basic principles of the law, adopt the self-government regulations and separate regulations to use the habits of the minority areas. The law is incorporated into the national law [3].

"If we think that writing hundreds of decrees can change the whole life of the countryside, then we will be fools." The operation of the national law is a complex process of internalization. Only the code can only produce functions. And efficiency, forced enforcement of the law is often only counterproductive. "In order to make the law known, we often need to be used as a supplement, because the concept used by the legislator needs to be explained by habit." In fact, any law must be interpreted to be applicable. There are many ways to interpret the law, and almost every law interpretation method is related to folk law. For example, to find out how the legislator intends to explain the law, after the legal text is formulated, the legislator's intentions cannot always be accurately ascertained from its written expression. Legislators have considered the specific content of customary law when they are enacted. However, the written expression is limited, and thinking is always richer than the connotation of words. The text itself is the sign of actual life. To find out the intention of the legislator must be combined with customary law. Even if it is a textual interpretation, it must be made to conform to the fact. Legal principles and flexible clauses, etc., are originally legislators adopting legislative techniques to enable judicial officers to interpret laws in accordance with social customs, customs, historical traditions, and moral standards, so as to make the law more flexible and manipulable, and to meet the needs of civil life. The real rule. For example, the "imperial clause" of civil law-the principle of good faith-if it is not explained and supplemented by a wide range of common-law rules, then it can only be an inexplicable legal fiction at best. Honesty and credit are not so much a legal principle as trading rules and moral principles. Under what circumstances is it honest and what constitutes credit depends on people's daily life experiences and relevant norms of folk law. "The principle of honesty and credit is based on good faith, sincerity, trustworthiness, fairness and reasonableness, and its substance is determined by the social conditions in a particular era." As for historical explanation, it is more inseparable from customary law [4]. When the law abandons customary laws that are used to consolidate the society and maintain the interests of the people, the state law may lose its own social foundation and authority, and it may be possible to potentially lose its effectiveness. The national law "must be in the original people. Germany to find a foothold."

At present, the conflict between the customary law and the national law in the western region, especially in ethnic autonomous areas, is mainly reflected in the "secondary justice". That is, disputes over cases resolved under the national law are due to conflicts between the national law and the common law of ethnic minorities. After the national judicial authorities made a judicial decision on the case, the minority party made a ruling in accordance with the customary law to retry the case. Although this ruling was made in a civil manner and did not have the legal effect in the sense of the state law, it was generally observed and implemented by members of ethnic minorities. The "secondary justice" phenomenon must be given high priority. We think there are two alternative solutions. One solution is to pay attention to the use of the mediation mechanism and its institutional innovation functions. The mediation system (including the people's mediation system, the private mediation system, and the judicial mediation system) is first and foremost a mechanism 
for disbanding disputes. It has a positive and important role in resolving widespread conflicts of interest and economic disputes. However, the mediation system is not merely a set of dispute resolution mechanisms. To a certain extent, it also plays a role in blocking the cultural communication between national law and customary law, providing a formal institutional dialogue channel for the positive interaction between the two. In the course of the operation of the mediation mechanism, it is possible to "provide opportunities for legal development through normative competition and choice, so as to bridge the gap between substantive law and norms of life". As for the ruling of civil mediation in resolving disputes, if it is in conformity with local customary law, which is in the interest of the country's overall interests, the national judicial authority will give the acquiescence [5]. This not only strengthens the legal protection of the parties, but also establishes the majesty of the national judicial authorities. Another solution is that ethnic autonomous areas should formulate single-line rules as soon as possible, or be authorized by the national legislature or the Supreme People's Court to use customary law by the judicial authorities in autonomous regions.

\section{Conclusion}

With the successful implementation of the country's western development strategy, the issue of the rule of law in the western region has become a key and difficult point for China's implementation of the strategy of administering the country by law. To explore the rule of law in the development of the western region, we must discuss it in the name of "diversification of law," and analyze in detail the value of the absence of national law and the cultural awareness of the common law of ethnic minorities.

\section{References}

[1] Montesquieu. The Spirit of Law (Volume One) [M]. Beijing: Commercial Press, 1963, 239.

[2] Wu Dahua, Xu Jie. The Legal Guarantee of Western Development [M]. Beijing: National Publishing House, 2001, 304, 307.

[3] Guan Guixia. Analysis of the problem of national economic autonomy in the development of western China [J]. Climbing, 2002(3): 55.

[4] E Wendong. The Convergence of Legal Culture in the Western Development[J]. Journal of the Armed Police Academy, 2001.

[5] Liang Zhiping. Law and Order in Rural Society [A]. Order, Justice and Authority of Rural Society [C]. Beijing: China University of Political Science and Law Press, 1997, 416. 